\title{
A EDUCAÇÃO BÁSICA NO BRASIL: vozes de professores da rede pública e privada
}

\author{
L'education de base au Bresil: les voix des \\ enseignants des reseaux public et prive
}

\author{
Abdeljalil Akkari ${ }^{\mathrm{a}}$, Camila Pompeu da Silva ${ }^{\mathrm{b}}$
}

\begin{abstract}
a Professor na área de Dimensão Internacional da Educação na Universidade de Genebra, Suíça e Consultor da IBE, Unesco, Genève, e-mail: djalil98@gmail.com

b Professora e Coordenadora de Arte do Ensino Fundamental no Colégio Marista Santa Maria de Curitiba, Curitiba, PR - Brasil, e-mail: camila.pompeu@uol.com.br
\end{abstract}

\section{Resumo}

Nas duas últimas décadas vimos surgir no Brasil um debate público sobre a necessidade de melhorar a qualidade do ensino na educação básica, em particular no ensino fundamental. Esse debate gira em torno essencialmente de três dimensões: (1) as medidas legislativas favoráveis à reforma do sistema educacional brasileiro que se traduzem pela adoção da LDB (Lei de Diretrizes e Bases); (2) as desigualdades estruturais ligadas aos financiamentos da educação pública e (3) a falta de compromisso dos poderes públicos em favor de uma educação básica. Sem negar a importância dessas três dimensões, nosso trabalho de pesquisa qualitativa está comprometido em explicitar a voz daqueles que não são mais ouvidos sobre o assunto: os professores e os diretores das escolas públicas e particulares. Realizamos 40 entrevistas não diretivas com

Rev. Diálogo Educ., Curitiba, v. 9, n. 27, p. 379-392, maio/ago. 2009 
estes atores da educação básica nos Estados de Goiás, Minas Gerais e Paraná. Estas entrevistas tinham por objetivo determinar o que provoca a qualidade ou a falta de qualidade do ensino, a partir do ponto de vista dos professores e dos diretores. Procuramos, em particular, analisar as escolhas atuais e potenciais dos professores da rede pública no que se refere à escolarização dos seus alunos. Este último ponto parece-nos extremamente importante porque acreditamos que é necessário um retorno das classes médias à escola pública para esperar uma melhoria do ensino público.

Palavras-chave: Educação de base. Professores. Qualidade. Ensino.

\section{Résumé}

Au cours des deux dernières décennies a commencé au Brésil un débat public sur ce qu'il faut pour améliorer la qualité de l'enseignement dans l'éducation de base, en particulier dans l'enseignement fundamental. Ce débat se développe sur trois axes: 1) les mesures legislatives en faveur de la réforme du système éducatif brésilien qui se traduisent par la LDB; 2) Les inégalités struturales liés au financement de l'éducation publique; 3) le manque d'engagement du pouvoir public en faveur de l'éducation de base. Sans nier l'importance de ces trois dimensions, notre travail de recherche qualitative veut donner la voix à ceux qui ne sont jamais entendus sur ce sujet: les enseignants et les directeurs des écoles publiques et privées. Nous avons réalisées quarante (40) enterviews non directives avec ces acteurs de l'éducation de base dans les Etats du Goiás, Minas Gerais et Paraná. Ces interviews avaient comme but celui de determiner ce que provoque la qualité ou le manque de qualité de l'énseignement du point de vue des enseignnants et des directeurs. Nous avons cherché, en particulier, d'analyser les choix actuels et potentiels des professeurs du réseau public en ce que concerne l'écolarisation de leurs élèves. Ce dernier point nous paraît extrémement important parce que nous croyons qu'il faut un retour des classes moyennes à l'école publique pourqu'on puisse attendre l'améliorement de l'enseignement public.

Mots-clés: Éducation de base. Enseignants. Qualité. Enseignement. 


\section{INTRODUÇÃO}

Esta pesquisa procurou levantar a visão que os professores da educação de base têm da sua profissão, da sua formação escolar e acadêmica e do que eles pensam sobre a escola de ensino fundamental no Brasil. Além disso, foram realizadas duas comparações: a primeira, entre as posições dos professores das redes pública e privada; e, a segunda, entre os professores que trabalham nas zonas rurais e os que atuam em zonas urbanas. Este projeto de pesquisa é realizado por uma equipe binacional da Suíça e do Brasil, e realizado no quadro do programa Research Partnerships between Swiss Universities of Applied Sciences and Developing and Transition Countries (KFH, Suíça).

No quadro das tentativas brasileiras e internacionais de melhorar a educação básica, esse artigo desenvolverá a reflexão sobre a necessidade de articular e levar em conta os fatores estruturais, realçando as contribuições dos atores locais incontornáveis (docentes, pais, diretores, alunos) e em particular os professores das redes pública e privada.

Este artigo está dividido em duas partes. Na primeira, procuraremos definir o que entendemos por qualidade de ensino básico no contexto brasileiro. $\mathrm{Na}$ segunda, apresentaremos uma visão geral dos resultados preliminares de nossa investigação in loco.

\section{O que significa qualidade da educação básica?}

Antes de mais nada, é fundamental definir o que entendemos por qualidade da educação. Consideramos de grande importância entender claramente o que significa uma educação de qualidade. Para identificar a qualidade na educação básica faz-se necessário considerar as várias dimensões que envolvem esta temática. Em primeiro lugar, ressaltamos que os parâmetros quantificáveis antecedem os parâmetros qualitativos, no caminho para uma educação de qualidade (BOGDAN; BIKLEN, 1994). Em outras palavras, percebemos que todos os sistemas de ensino atualmente reconhecidos por sua qualidade, começaram desenvolvendo o acesso maciço à escola (COHEN; MANION, 1990). A história do modelo escolar contemporâneo, incluindo o da Europa, se caracteriza por salas superlotadas e de uma expansão significativa no número de matrículas. Pode-se pressupor que o atual progresso quantitativo feito pelo Brasil nos últimos anos poderá revelar sua eficácia no futuro.

No entanto, uma tendência internacional equivocada, do nosso ponto de vista, tornou a qualidade da educação equivalente aos indicadores quantitativos utilizados para medir o desempenho do aluno. Em nível internacional é o estudo

Rev. Diálogo Educ., Curitiba, v. 9, n. 27, p. 379-392, maio/ago. 2009 
PISA da OCDE que se destaca. No Brasil, muitos instrumentos têm surgido nos últimos anos: Prova Brasil, ENEM, etc. (MOREIRA, 1998).

Parece-nos que a qualidade da educação básica aponta, principalmente, no sentido e no valor que os alunos e profissionais da educação dão às atividades escolares, isto é, por exemplo, se vale a pena aprender ou não a matemática, a arte, o português. Várias dimensões devem estar presentes para obter uma educação de qualidade.

Primeiramente, os estudantes que vão à escola estão em busca de aprendizados que sejam úteis tanto para aplicar em suas comunidades quanto na sua escolaridade futura. Também é importante saber se eles têm tido prazer em frequentar a escola ou se a veem apenas como entediante, mas necessária. Em segundo lugar, é evidente que a qualidade da educação é medida pela homogeneidade dos serviços que são oferecidos às escolas, aos estudantes nos seus diferentes grupos sociais, em todo o território nacional. Ao mesmo tempo, não é mais necessário fazer pesquisas para observar que a qualidade da educação básica no Brasil se diferencia, nas redes municipais, estaduais e nas instituições privadas. Do mesmo modo, também é sabido que as crianças do Norte e Nordeste não recebem, na maioria das vezes, uma educação de qualidade quando comparada à educação das crianças no Sul ou Sudeste. Por último, mas tão importante quanto as demais dimensões, pois isto é o que mais queremos ressaltar no presente artigo, é que a qualidade da educação não é possível sem um corpo docente respaldado, devidamente pago, profissionalmente habilitado e socialmente reconhecido, na sua missão educadora.

\section{Escutar a voz dos professores}

Durante a realização das entrevistas (GHIGLIONE; MACARON, 2001), em diversas escolas da rede pública e privada, pudemos constatar alguns resultados preliminares que apontam para uma mesma direção: precisamos ouvir a voz dos nossos educadores. O que eles falam é a pura realidade do cotidiano escolar. São eles que estão na linha de frente de todo o processo educacional. Sendo assim, a qualidade não pode ser avaliada sem ouvir suas vozes, as vozes do atores principais deste processo, os professores.

A seguir, apresentaremos um mapeamento geral do discurso dos professores sobre a qualidade da educação básica.

Ressaltamos ainda, que todos os entrevistados participaram sem resistência e demonstraram satisfação em colaborar com o estudo.

Foi realizado também um seminário para os professores que participaram das entrevistas com o propósito de proporcionar debates que

Rev. Diálogo Educ., Curitiba, v. 9, n. 27, p. 379-392, maio/ago. 2009 
contribuíssem para a melhoria das análises dos dados coletados. A participação dos professores contribuiu muito para a validade dos dados e análises apresentadas.

\section{Ser professor, para quê? Entre a vocação e a falta de opção}

Uma das primeiras questões colocadas aos professores, participantes das entrevistas, foi sobre o que o levou a ser professor, sobre o porquê da escolha da profissão docente: quais os contextos que envolveram essa decisão; se houve pessoas marcantes que influenciaram na decisão ou se simplesmente foi a última opção profissional. Percebemos uma diversidade na modalidade de entrada na profissão.

As entrevistadas identificadas pelos números 2, 12 e 23, exemplificam a fala da escolha da profissão por vocação, paixão pelo que faz.

Foi vocaşão mesmo! Essa já veio desde criança, eu dava aula até para as bonecas, como se diø, o instinto mesmo de vocação (ENTREVISTADA 2).

A minha escolha é porque eu amo de paixão dar aula, e eи me sinto muito gratificada quando eu consigo transmitir um pouco do que en sei para os meus alunos e assim, além do mais, eu acho assim que o professor de certa forma é um formador de opinião, e os profissionais desta área eles têm que dar aula por paixão porque se for olharpelo aspecto financeiro ele tem que casar bem para executar a função por prazer (ENTREVISTADA 12).

Foi por vocação mesmo, desde criança gostei muito, foi vocação e não acidente (ENTREVISTADA 23).

No entanto, a tendência aponta para uma seleção da carreira docente como uma escolha de segunda categoria. Parece antigo o tempo quando os cursos de pedagogia recrutavam os estudantes mais ativos e os mais engajados no estudo. $\mathrm{E}$, com a massificação do ensino, a profissão tende a não recrutar mais aquelas pessoas realmente interessadas nela. O ensino torna-se uma "ocupação pela falta de algo melhor para fazer". Isso aparece nos comentários das entrevistadas 24 e 25:

Eu não escolbi, foi o único curso que tinha segundo gran era o magistério, não queria fazer de forma alguma, minha mãe disse que en tinha que fazer. A escola era muito bonita, de freira e dai eu fiæ: Ao terminar o magistério comecei a fazer serviço social na zona rural e dai eu me interessei pela população, mas eu não escolbi ser professora (ENTREVISTADA 24).

Rev. Diálogo Educ., Curitiba, v. 9, n. 27, p. 379-392, maio/ago. 2009 
Primeiramente foi uma falta de oportunidade de trabalho que tinha na minha região, antigamente ou a mulher era professora ou dona-de-casa, eu prefiro ser professora [...] a escola foi a única opção que en tive (ENTREVISTADA 25).

Tem sido recorrente essa questão em diversos países preocupados em saber quem é recrutado para exercer a profissão docente. Percebemos que a origem social dos futuros professores sofreu alterações, no sentido da sua democratização.

Não se pode construir em um país uma educação de qualidade formada por um corpo docente que escolheu estar nesta profissão por falta de opção ou por que é um dos cursos com a mensalidade mais baixa dentre os demais, no caso das faculdades particulares. Isso contribui para a falta de qualificação dos profissionais formados para área educacional.

\section{Formação inicial}

A respeito da formação docente, constatamos que no Ocidente, há uma elevação do nível de formação dos professores. Mesmo se há ainda certos observadores que consideram que ser professor é uma vocação desde o nascimento, a maioria das análises constatou que a formação é necessária e que ela pode fazer a diferença na aprendizagem dos alunos, sobretudo dos menos favorecidos.

Entretanto, é importante destacar que as formações atuais dos professores não são satisfatórias em todo o mundo. Duas críticas essenciais são emitidas quando se fala na formação docente:

\section{a) Ênfase sobre a teoria sem conexão com o ofício}

A formação é frequentemente teórica e desconectada do trabalho do professor. Ela deixa pouco espaço para a formação prática e para a aprendizagem das principais tarefas do ofício de professor.

\section{b) Falta de integração dos diferentes elementos da formação}

Os programas de formação são frequentemente uma adição de elementos distintos sem coerência no seu conjunto. Estes elementos não são verdadeiramente apropriados para os futuros professores, ou seja, não fazem sentido algum para o futuro professor (BRASIL, 1/02).

Como vimos, à formação inicial dos professores permanece ainda muito desconectada da prática. Em outras palavras, o que aprendem na teoria não tem relação com a aplicação no cotidiano escolar.

De modo geral, para os entrevistados, a formação inicial não contribuiu para a atuação na sala de aula. Porém, existe uma avaliação diferenciada

Rev. Diálogo Educ., Curitiba, v. 9, n. 27, p. 379-392, maio/ago. 2009 
conforme a formação recebida e a experiência profissional anterior à formação inicial. Percebemos esse aspecto em várias entrevistas realizadas. Os professores que fizeram o curso de magistério e que tiveram experiência com alunos antes de se formar em curso superior, avaliaram de forma positiva o aporte de sua formação. Comentam que o magistério foi o curso que deu o suporte necessário para lidar com questões básicas do dia-a-dia na escola. Já os professores que fizeram somente o curso superior, são mais críticos no que diz respeito à contribuição da formação inicial na qualidade de seu desempenho. Esses dois trechos das entrevistas demonstram esse paradoxo entre teoria e prática na formação do docente:

O que ensina na faculdade é uma coisa e o que você trabalha na realidade é outra, completamente diferente. Porque lá a gente vê a parte teórica o professor ensina a teoria prá gente. A maneira de dar aula, isso ai você adquire com sua prática com babilidade. [...] Eu sei que a realidade da escola é uma e o que ensina na faculdade, não é bem outra, tem um parâmetro mas assim, tem uma diferença, é diferente, ajuda pouco ela deveria trabalhar mais a forma da gente entrar na sala de aula de trabalhar com o aluno. Isso é uma grande dificuldade que a gente tem (ENTREVISTADA 2).

Não, a formação acadêmica contribui pouco, muito longe da realidade que tem em sala de aula. A formação que tenho foi muito mais como curso de capacitacão do que curso de pedagogia [...] é muito mais prático do que o curso de pedagogia. O curso de pedagogia para prática em sala de aula quase, nada muito longe fica muito na teoria. Amplia o horizonte como profissional [...] estuda autores, momentos da educação do país, mas a realidade dos meus alunos aprendi fora, nos cursos no dia-a-dia (ENTREVISTADA 8).

Como podemos ver, o desafio para o curso de pedagogia é grande. Como integrar essa dura avaliação do docente ao programa de sua formação !? Diante disso, uma coisa é certa, os cursos de pedagogia não podem continuar assim, com essas mesmas ideias acerca da formação do educador. É ncessário repensar outros caminhos para este curso, caminhos que favoreçam uma formação mais consistente.

\section{Reconhecimento profissional}

Sobre a questão do reconhecimento social do professor, foi unânime entre os professores entrevistados que a profissão docente não tem o seu devido reconhecimento social. E, além disso, este reconhecimento apresentou um declínio ainda maior nas últimas décadas. Ela piorou, porque há quinze anos falar que era

Rev. Diálogo Educ., Curitiba, v. 9, n. 27, p. 379-392, maio/ago. 2009 
professor era importante. Isso mudou por conta do governo que desvalorizou a nossa profissão. (ENTREVISTADA 21).

Há uma imagem negativa da figura do professor, como alguém que tem um trabalho penoso, sofrido e que exige uma carga de paciência extrema.

Na sociedade os professores são muito desvalorizados, quando você vai sentar numa roda para conversar Nossa! Mas você éprofessora?' Parece que está nadando contra maré. "Nossa! Mas não teve outra oportunidade de trabalho? Você não quis outra formação? Nossa! Então você queria era nada com a dureza'. Você não procurou outro caminho foi por um mais fácil, de dar aula. Foi por isso que você fez pedagogia então? Curso de espera marido'. Você escuta muito essas coisas (ENTREVISTADA 9).

Acho que é vista como uma profissãozinha, que não tem uma grande importância, que ela não está a altura de um médico de um [...] cirurgião qualquer aí, então é isso, é uma profissão que está a menos assim, e isso tem haver com assim, eu acho que é uma profissão que não é tão bem paga [...] o salário já discrimina o profissional no mercado, então nesse sentido eu acho que não receber assim, é, tão bem, eu acho que já determina uma discriminação na profissão (ENTREVISTADA 10).

A sociedade hoje tem uma visão completa ele é professor [...] Um cidadão comum sem importância nenhuma. Na nossa comunidade o professor está comparado a serviçal qualquer a única função nossa e educar o filho, se a gente educou bem a gente tem um valor sim. Se a gente conseguiu fazer aquele aluno aprender alguma coisa levou ele a um nivel elevado de aprendizagem a gente até tem valor, mas se e aquele aluno que não tem vontade não tem nada agente não tem valor a culpa é nossa que não conseguiu (ENTREVISTADA 2).

E, relacionada a isso, está a questão salarial. Muitos entrevistados acreditam que a falta de reconhecimento justifica também os baixos salários e até mesmo as diferenças salariais entre professores de séries iniciais e professores universitários, ou ainda entre professores da rede pública e os da rede privada.

Sobre esse último ponto, há também um consenso entre os entrevistados de que o reconhecimento social do professor está diretamente relacionado à rede de ensino onde ele atua (municipal, estadual ou privada). Cabe aqui uma interessante reflexão procedente das análises de algumas entrevistas: o reconhecimento, sob a ótica salarial, é relativamente maior quando se trabalha em uma escola de grande porte, amplamente reconhecida na rede privada de ensino,

Rev. Diálogo Educ., Curitiba, v. 9, n. 27, p. 379-392, maio/ago. 2009 
mas ao mesmo tempo não é reconhecida enquanto possibilidade de profissão para os alunos dessas escolas. Ou seja, a profissão é reconhecida pela classe alta como importante para a formação de seus filhos, mas não com perspectivas de profissão para esta classe, nesse aspecto ela é descartada. Já na rede pública, acontece o inverso, há o reconhecimento da função de profissão, mas não no aspecto salarial. O respeito e a valorização são somente no âmbito da contribuição para a formação.

Sobre os aspectos acima relatados, destacamos o comentário de um professor da rede privada de um grande colégio na cidade de Curitiba:

\begin{abstract}
[...] depende muito do meio social o teu reconhecimento. Eu vou dižer pra você assim: Em alguns meios há o reconhecimento e uma valorização grande, vou dizer que um meio social de uma camada [...] eu vou chamar de uma classe menos privilegiada, ainda é mais reconbecida a profissão. Um meio social de uma classe social já mais privilegiada, é menos reconbecido no sentido econômico, mas enquanto função é reconbecido. Enquanto contribuição de formação. Agora, se você fala nesse meio (classe média-alta) enquanto possibilidade de uma profissão, dai sim ela é descartada. No meio social com a classe média-alta. A maioria diæ: "não, não quer isso pra mim [...]' 'Porque normalmente eles associam a função com a questão financeira. Agora, já enquanto necessidade é visto como necessário sim' (ENTREVISTADO 32).
\end{abstract}

Alguns entevistados levantam ainda a questão da falta de reconhecimento não somente da sociedade, mas dos próprios alunos. Em sala de aula ou no ambiente escolar como um todo, o professor é desvalorizado. Há uma relação entre o desrespeito ao professor por parte dos alunos, das famílias e a falta de reconhecimento da profissão de professor. Professores de escola privada, relatam a dificuldade de se trabalhar com a constante interferência dos pais em seu trabalho. Há um descrédito da palavra do professor.

O que en percebo é assim: por exemplo, aqui o professor aqui em sala de aula, quando tem essa interferência de pais, querendo ou não, é um descrédito em relação à palavra do professor. Quando um professor diz assim: "seu filho não vai bem [...] tem essas e essas dificuldades [...] por isso e por isso". Quando o pai vem com essa interferência no sentido de contrapor, de que ele não pode dizer isso, que ele não tem o direito de mencionar essas coisas [...] de dar essas tarefas que são excessivas [...] No fundo é uma palavra de desvalorização. Quer dižer ele não vai chegar para um médico e dizer assim que ele não pode receitar isso para o meu filho. Agora o professor não tem o direito de fazer essas observacões, que são

Rev. Diálogo Educ., Curitiba, v. 9, n. 27, p. 379-392, maio/ago. 2009 
vistas e vivenciadas em sala de aula. Então a palavra do professor parece que não tem importância (ENTREVISTADO 37).

Com tudo isso, percebemos que a profissão docente não é reconhecida da maneira como deveria ser. É considerada como uma profissão que envolve sofrimento, sacrifícios, vocação de quem a escolhe e, ao mesmo tempo, também é a última opção profissional de muitos, possibilitando a atuação de qualquer um. Retomando as palavras de nossos interlocutores, que dizem ouvir muito que esta é uma "profissãozinha" e que o curso de pedagogia é um curso "espera marido", reduzindo assim, a credibilidade do curso.

Entretanto, para os que estão nesse ambiente docente, e portanto, sabem das dificulades da profissão, entre seus pares, ainda existe algum reconhecimento.

\section{Salário: injusto?}

Ao perguntarmos sobre a existência da relação entre o salário do professor e a educação que ele oferece e qual seria o salário justo para o trabalho que ele desempenha, percebemos que a insatisfação com a remuneração é generalizada entre os entrevistados. Eles são unânimes em dizer que o salário atual do professor não é justo e não permite uma vida digna. Para que possam manter um bom nível de vida, precisam fazer dupla ou até tripla jornada de trabalho. Isso causa um grande desgasto de energia que pode prejudicar a qualidade da educação que oferecem.

Entretanto, os professores disseram que não há uma relação mecânica entre salário e desempenho. Ou seja, mesmo com baixos salários a qualidade no ensino que oferecem não é necessariamente menor. Mesmo sendo mal pagos se empenham ao máximo na sala de aula.

Um salário justo, segundo os professores entrevistados, seria aquele que possibilitasse condições mínimas de sobrevivência, bem como também ter condições de comprar uma casa, livros, participar de cursos, congressos, viajar para fazer cursos fora, que permitisse ter um plano de saúde e ainda alguma forma de lazer.

Uma entrevistada ressalta ainda a relação entre o salário e a mobilização do professor para sua atualização. Sobre qual seria o salário justo para o professor ela ressalta que:

É o salário na medida do que você estuda, do que você se atualiza. Eu acho que tem que ser isso. O teu plano tem que ser assim: quais são as suas formacōes, só que não a quela coisa que professor universitário faz, que faz um monte de inscriçöes de projetos pra ter no negócio![...] então, eu acho que não é o correr atrás, mas assim a gente ter uma

Rev. Diálogo Educ., Curitiba, v. 9, n. 27, p. 379-392, maio/ago. 2009 
avaliação de desempenho, uma avaliação acadêmica do educador, que isso componba a sua gratificaşão. E principalmente o que você faz como mobilização social. Eu acho que se hoje em dia pra entrar na universidade a questão do voluntariado está inserida no curriculo desse menino, do professor, não que tivesse o voluntariado, mas que tivesse transformações e ações sociais educativas. Você conseguiu transformar o que? Então eu acho que a medida do salário justo é a medida da tua capacitação (ENTREVISTADO 33).

\section{Projeto político pedagógico e sua operacionalização}

A maioria dos professores entrevistados comentou que o Projeto Político Pedagógico (PPP) contribui significativamente para a qualidade da educação na escola. Foi consenso entre os professores a afirmação que o Projeto pedagógico é imprescindível para os rumos da escola, para oferecer as linhas e as diretrizes a serem seguidas.

Muitos relatam que o projeto é um parâmetro, algo em que você pode se apoiar para seguir e dar continuidade ao trabalho. E que deve ser dinâmico, estar em constante construção.

Entretanto, alguns professores observam que o processo de produção do PPP é um processo "de cima (Secretaria de Educação, inspetores, diretores, etc.) para baixo (docentes)." Dessa maneira, muitos PPP fogem da realidade cotidiana do professor, porque é feito por quem não está efetivamente em sala de aula. Isso acaba colocando algumas dificuldades na utilização do PPP pelo professor.

O problema do PPP não é sua existência, mas sua operacionalização na sala e no trabalho cotidiano do professor, como observa essa professora:

Só que o que a gente talvę não consegue comunicar é mostrar que
o PPP, ele está ligado à organização curricular, [...] não só
conteúdo [...] à gestão de aula, a que você elege como conteúdo. O
que você elege como conteúdo tem a ver com posicionamentos teóricos
com o que vocie escolbe, com que tipo de educação você quer [...] Eu Eu
acho que a grande dificuldade é fazer com que o professor entenda
que ele é o projeto politico pedagógico. E não é uma coisa construída
para que as pessoas atuem (ENTREVISTADO 33).

Por isso, é importante ressaltar ainda que, ao se trabalhar com o PPP na escola, deve-se ter cuidado para que o mesmo não se torne uma mera cobrança pedagógia, deixando uma autonomia parcial para os professores. Ele não deve ser encarado como um instrumento de controle das ações do professor e sim como mobilizador, inspirador dessas ações.

Rev. Diálogo Educ., Curitiba, v. 9, n. 27, p. 379-392, maio/ago. 2009 


\section{Relação escola - família}

No que se refere à colaboração família-escola, existe um grande contraste entre rede pública e privada. Os professores apontam uma omissão por parte de algumas famílias, especialmente nas escolas públicas, comentam que existe até um certo descaso por parte dos pais.

Já na escola particular, a relação que tem se desenvolvido entre escola e pais é uma relação de clientela, de "terceirização" dos filhos como relatam alguns professores. Há uma sobrecarga no papel do professor. A família requer da escola funções que antes eram da família. Como se o professor e a escola fossem os únicos responsáveis pela educação das crianças e jovens. Por isso, na rede privada, os pais estão mais presentes devido a essa exigência de uma educação em todos os aspectos, educação que a família não promove em casa e que a escola deveria dar conta. Cobram, pois estão pagando por um serviço e querem ver o retorno.

Ao mesmo tempo, na educação pública, também existe esta necessidade de uma educação ampla, não só em aspectos cognitivos. A família reconhece isso, mas não cobra porque como é um serviço gratuito, qualquer coisa que for feito está bom, dando a entender que ainda há o sentimento de que o que é público não se pode interferir muito, somente agradecer pelo que tem.

\section{Conclusão: como validar esses resultados?}

Com as reformas educacionais desencadeadas a partir dos anos de 1990, os professores são muito visados pelos programas dessas reformas enquanto agentes centrais da mudança na qualidade da educação. Mas, se veem constantemente constrangidos diante desta responsabilidade pelo êxito, ou insucesso dos programas.

As entrevistas nos mostraram que os professores são cobrados pela melhoria da qualidade da educação, entretanto, as condições de trabalho proporcionadas para os mesmos, não correspondem às suas reais necessidades no desenvolvimento de um trabalho de qualidade na escola. Além disso, o professor muitas vezes se vê sozinho para a realização desse empreendimento.

Ao lado dessa impossibilidade de exercer corretamente seu ofício, o professor atualmente é confrontado com um público diferente, procedente da massificação. Existe no mundo um consenso em dizer que a ascensão social está parada. A massificação dos estudos não significa democratização da educação, não significa nem mesmo uma educação básica de qualidade para todos.

Por toda parte no mundo, desigualdades gritantes estão ocorrendo, dentre elas rede pública/rede privada; escola para minorias étnicas e imigrantes;

Rev. Diálogo Educ., Curitiba, v. 9, n. 27, p. 379-392, maio/ago. 2009 
escolas que preparam para a universidade/escolas que formam para o trabalho, entre outras (ARELADO, 2005).

A análise das entrevistas tornou evidente uma contradição no âmbito da escola: de um lado, exige-se dos docentes atualização, disposição e adaptação para enfrentarem e se adequarem às mudanças implementadas. A formação continuada é exigida e valorizada. Todavia, não são proporcionadas as condições para sua efetivação. A formação, na grande maioria dos casos, fica sob a responsabilidade do próprio professor que, como vimos nos relatos dos entrevistados, o salário oferecido não dá condições para tal formação. Com seus salários reduzidos, fica praticamente inviável darem conta de sua sobrevivência e ainda manterem-se atualizados. As entrevistas mostraram, também, a necessidade de reformar os programas de formação de professores a partir do trabalho real do docente na sala de aula. Em outras palavras, um curso de pedagogia não pode ser um conjunto de receitas teórico-pedagógicas, mas deve incluir as questões práticas, bem como a gestão de classe do quotidiano escolar.

As duas iniciativas mais importantes no âmbito do ensino fundamental no Brasil nestes últimos anos são, sem dúvida, (1) a implementação do Fundo de Manutenção e Desenvolvimento do Ensino Fundamental e de Valorização do Magistério - Fundef; e (2) o lançamento do FUNDEB - Fundo de Manutenção e Desenvolvimento da Educação Básica e de Valorização dos Profissionais da Educação, que terá a duração de 14 anos (2006-2019). Essas iniciativas certamente irão melhorar a educação infantil, o ensino fundamental e médio, bem como a educação de jovens e adultos. No entanto, é necessário mobilizar os professores por meio de um melhor reconhecimento do seu papel e melhorar as suas condições de trabalho. Além disso, o sistema educativo brasileiro deve atrair professores com motivação para o ensino e não simplesmente pela falta de opções.

Por meio desta pesquisa, constatamos a forte necessidade de proporcionar momentos de troca entre os professores e pesquisadores, que muitas vezes realizam suas pesquisas e não compartilham com os mais interessados, aqueles que participaram e que foram objeto essencial e todo o processo investigativo: os professores. É necessário transformar a tradição da pesquisa educacional que vigora no Brasil: menos análises de documentos oficiais e mais levantamentos de dados na realidade cotidiana do docente de Educação Básica. Parece-nos urgente que os universitários saiam dos seus gabinetes para ouvir os professores e dialogar com eles. É comum realizar discursos prescritivos sobre os professores ou sobre como deve ser um bom professor. No entanto, é tempo de entender a voz da prática, a voz da ação pedagógica diária e trabalhar com os professores.

Por fim, desejamos ainda, insistir no fato de que a missão de instruir não pode ser jamais separada da missão de educar.

Rev. Diálogo Educ., Curitiba, v. 9, n. 27, p. 379-392, maio/ago. 2009 


\section{REFERÊNCIAS}

ARELADO, L. R. G. Educação no século XXI: tendências e perspectivas. Revista Impulso, v. 16, n. 39, p. 37-55, 2005.

BOGDAN, R.; BIKLEN, S. Investigação qualitativa em educação. Porto: Porto Editora, 1994.

BOURDÉ, G.; MARTIN, H. Les écoles historiques. Paris: Seuil, 1983.

BRASIL. Leis e Diretrizes e Bases da Educação Nacional. Lei 9.394/96, 20 dez. 1996. Estabelece as diretrizes e bases da educação nacional. Diário Oficial da União, Brasília, ano 134, n. 248, p. 27833-27841, 1996.

. Resolução CEB 2/98. Institui as diretrizes para o Ensino Fundamental. 1998. Diário Oficial da União, Brasília, 07 abr. 1998. Seção 1, p. 31, 1998.

Resolução CP 1/02. Institui Diretrizes Curriculares Nacionais para a formação de professores da educação básica, em nível superior, curso de licenciatura, de graduação plena. 2002. Diário Oficial da União, Brasília, 4 mar. 2002, Seção 1, p. 9, 2002.

COHEN, L.; MANION, L. Métodos de investigación educativa. Madrid: La Muralla, 1990.

GHIGLIONE, R.; MATALON, B. O inquérito: teoria e prática. Oeira: Cela, 2001. MESQUIDA, P.; SANTOS, M. S. As matilhas de Hobbes. São Paulo: EDUMESP, 2007.

MOREIRA, P. F. B. A psicologia e o resto: o currículo segundo César Coll. Cadernos de Pesquisa, n. 100, p. 93-107, 1997.

PATTON, M. Q. Qualitative evaluation and research methods. Newbury Park: Sage, 1990.

Recebido: 27/03/2009

Received: 03/27/2009

Aprovado: $21 / 04 / 2009$

Approved: 04/21/2009

Revisado: 22/07/2009

Reviewed: 07/22/2009

Rev. Diálogo Educ., Curitiba, v. 9, n. 27, p. 379-392, maio/ago. 2009 